\title{
Activity of Hepatic Galactose-Metabolizing Enzymes in the Pregnant Rat and Fetus
}

\author{
SHIRLEY R. ROGERS, BRAD W. BOVEE, STEVEN L. SAUNDERS, AND STANTON SEGAL \\ Division of Biochemical Development and Molecular Diseases, Children's Hospital of Philadelphia, and \\ Departments of Pediatrics and Medicine, University of Pennsylvania School of Medicine, Philadelphia, \\ Pennsylvania 19104
}

\begin{abstract}
The sp act of hepatic galactose-metabolizing enzymes, galactokinase, galactose-1-phosphate uridyltransferase, and uridine diphosphate-4-epimerase were measured in female rats during pregnancy and lactation as well as in fetuses and pups after parturition. Sp act for transferase and epimerase in pregnant rat liver are about $50 \%$ higher than that of virgin females, and with the increase in organ size during pregnancy the total hepatic activity is double that of nonpregnant animals. Galactokinase activity decreases somewhat during pregnancy, but total activity is $25 \%$ higher than in virgin liver. A Michaelis-Menten kinetic analysis of liver transferase indicates an increase in the maximum velocity of the reaction without a change in $\mathrm{Km}$. Isoelectricfocusing on a high-resolution IEF gel demonstrated similar isozyme patterns. The sp act of the fetal liver enzymes increase to about twice that of the maternal tissue, but total activities are low due to the very small fetal liver size. Sp act of these enzymes in maternal liver fall after delivery, but sp act of galactokinase and transferase are programmed to increase in liver of the growing neonatal animals, reaching levels almost 5-fold higher than found in nonpregnant adult liver. An understanding of factors contributing to the enhanced transferase activity of the liver of pregnant and neonatal rats may contribute to possible ways of augmenting the residual transferase activity of patients with transferase-deficient galactosemia as a therapeutic strategy. (Pediatr Res 25:161-166, 1989)
\end{abstract}

Abbreviations

Galactokinase, (EC 2.7.16)

Transferase, galactose-1-phosphate uridyltransferase (EC 2.7.7.12)

Epimerase, uridine diphosphate galactose-4-epimerase (EC 5.1.32)

UDPglucose, uridine $5^{\prime}$-diphosphoglucose

Galactose-1-P, $\alpha$-D-galactose-1-phosphate

IEF, isoelectric focusing

The feeding of a high galactose-containing diet to pregnant rats has been used as a model to study in utero galactose toxicity in the fetus and newborn $(1,2)$. The focus of such research has centered mainly on neonatal toxicity with little regard for galactose effect on the pregnant mothers. Several pertinent findings,

Received January 22, 1988; accepted September 29, 1988.

Correspondence Stanton Segal, M.D.. Division of Biochemical Development and Molecular Diseases. The Children's Hospital of Philadelphia, 34th and Civic Center Boulevard. Philadelphia. PA 19104

Supported by National Institutes of Health Grant HD 08536. however, have been made indicating galactose metabolism may be different in pregnant animals. We have observed that cataracts do not develop in pregnant rats fed a high galactose diet for the 21 days of gestation, whereas they are found in young male rats fed the same diet for the same number of days $(2,3)$. Others have reported that pregnant rat lenses are clear until $48 \mathrm{~h}$ after parturition when cataractous changes precipitously appear (4). These data suggest that pregnancy affords protection of the female from galactose toxicity. Although extensive investigations of glucose metabolism have been made in the pregnant rat (57), little is known about galactose metabolism in the gestational state. Therefore, we have examined the sp act of the galactosemetabolizing enzymes galactokinase, transferase, and epimerase in the liver of dams throughout pregnancy and lactation and in the fetus for comparison. The results form the basis of this report.

\section{MATERIALS AND METHODS}

Timed-pregnant rats of the Sprague-Dawley strain were purchased from Charles River Breeding Laboratories, Inc., Wilmington, MA) and housed in our facility until the pups were weaned at age 21 days. These offspring were the animals used in the virgin and pregnant groups. Females were separated into two groups: the first was maintained in a virginal state and the second was bred at maturity to nonlitter-mate males. At specified times during pregnancy and lactation, livers were obtained, and enzyme activities were compared with those from age-matched virgin females. Animals were killed by exsanguination, livers rapidly excised and frozen by freeze-clamping in Wollenberger tongs precooled in liquid nitrogen. Adult animals were fed stand.ard laboratory food and water ad libitum, whereas suckling rats remained with a lactating mother.

Biochemicals and enzymes of the highest purity were obtained from Sigma Chemicals Co. (St. Louis, MO), ampholytes from LKB Instruments, Inc. (Gaithersburg, MD), and radioisotopes from Amersham Corp. (Arlington Heights, IL). All other chemicals of the highest purity available were purchased from local suppliers.

Particulate-free supernatants containing the soluble enzymes were assayed as follows: galactokinase was measured by the method of Cuatrecasas and Segal (8), transferase by that of Bertoli and Segal (9), and epimerase according to Rogers and Segal (10). Protein concentrations were determined using the coumassie blue reagent kit supplied by Bio-Rad Laboratories (Rockville Center, NY). Enzyme sp act are expressed as nmol of product formed $/ \mathrm{min} / \mathrm{mg}$ soluble protein. Although the wt of the liver increases during pregnancy, we and others $(11,12)$ have found that the concentration of protein/g of liver remains constant. Therefore, protein content appears to be a valid parameter for comparing activities. Values for total activity/liver were calculated by multiplying the sp act/mg of soluble protein by the protein content/g and the liver wt in $g(11,12)$. 
Measurement of the velocity-substrate concentration dependence of transferase and determination of the apparent MichaelisMenten constants were carried out over a substrate concentration range of 0.1 to $2 \mathrm{mM}$. To simplify the calculation of enzyme velocities in this bisubstrate reaction and to eliminate isotope dilution as a factor, the radiolabeled substrate was kept at a fixed concentration; the concentration of the unlabeled substrate was varied. Thus, UDP $\left[{ }^{14} \mathrm{C}\right]$ glucose was the fixed substrate when galactose-1-P was the varied substrate, and $\left[{ }^{14} \mathrm{C}\right]$ galactose-1-P was fixed when UDPglucose was varied. Determination of $V_{\max }$ and $\mathrm{Km}$ values for each animal tested were calculated using linear regression analysis where data exhibiting substrate inhibition was excluded.

IEF was performed with a $105 \times 115 \times 0.8 \mathrm{~mm}$ polyacrylamide gel using a $4 \% \mathrm{pH} 5.0-7.0$ plus a $1 \% \mathrm{pH} 3.5-9.5$ range as detailed by Kelly et al. (13) except that the gel was prefocused at $5 \mathrm{~W}$ for $30 \mathrm{~min} 20 \mu \mathrm{l}$ of sample applied and run for $3 \mathrm{hrs}$ at $5 \mathrm{~W}$. The gel was stained for transferase activity by the agarose overlay method of Sparkes et al. (14).

The data presented are the averages \pm SEM for $n$ animals except for fetal tissue. In this case, livers from the entire litter of pups were pooled; therefore, $n$ is the number of litters. All assays were performed in duplicate. One-way ANOVA and Student's $t$ test of unpaired means and SEM was used to compare the sp act of each enzyme found in livers of the nonpregnant group with that found at each state of pregnancy and lactation. In addition, effects of the change from the pregnant state to nursing mother were assessed by comparing activity in lactating mothers with that found at term. A $p<0.05$ was an acceptable difference to establish a level of significance.

\section{RESULTS}

Enzyme activity during pregnancy and lactation. The changes in specific activities of hepatic galactokinse, transferase, and epimerase in virgin, 7 to 20 -day pregnant and postpartum rat liver are shown in Figure 1. Levels of galactokinase activity found in virgin rats were $6.97 \pm 0.25(n=15) \mathrm{nmol} \times \mathrm{min}^{-1} \times \mathrm{mg}$ protein $^{-1}$; whereas levels in pregnant rats varied between 4 and 5 until term when it was $5.71 \pm 0.42(n=10)$. In contrast to galactokinase, transferase levels increased from $12.57 \pm 0.44(n$ $=15) \mathrm{nmol} \times \mathrm{min}^{-1} \times \mathrm{mg}$ protein ${ }^{-1}$ in the virgin liver to values ranging between 17.02 and 20.18 throughout pregnancy. Results from ANOVA for transferase at various days of pregnancy indicate that activity does not change statistically during pregnancy. The mean for the entire group of pregnant animals is $18.88 \pm 0.57$ and differs from that of the virgin (shown above) with a $p<0.001$. The higher transferase $\mathrm{sp}$ act in the pregnant liver was not due to the presence of an activator because enzyme assays of a 1:1 mixture of homogenates from the tissue of virgin and pregnant animals yielded the expected average of values obtained from assay of each tissue alone. Epimerase activities paralleled the pattern observed for transferase, increasing significantly from $3.36 \pm 0.19(n=15) \mathrm{nmol} \times \mathrm{min}^{-1} \times \mathrm{mg}_{\text {protein }}{ }^{-1}$ in the virgin to $6.46 \pm 0.72(n=7)$ at term $(p<0.001)$.

Figure 2 shows a comparison of the ranges of enzyme activities for virgin and term maternal livers. For galactokinase, more than half of the 10 preterm values were in the virgin range; the remainder were lower than levels in virgin liver. Transferase at term ranged from 15.07 to $26.84 \mathrm{nmol} \times \mathrm{min}^{-1} \times \mathrm{mg}$ protein ${ }^{-1}$ with practically no overlap with values in the virgin liver. The data for epimerase activity reveal that whereas overlap of values in pregnant liver with the range in virgin tissue is observed, the pattern of values suggested there might be a discontinuity of epimerase activity in pregnant liver with half of the livers being in the virgin range and half clearly higher. The distribution of values, however, obtained at other days of pregnancy were not consistent with this possibility.

Total liver activity for the three enzymes is shown in Table 1. Because the liver is the primary organ involved in the conversion of galactose to glucose, expressing activity per whole liver indicates the total capacity of the animal to metabolize galactose.

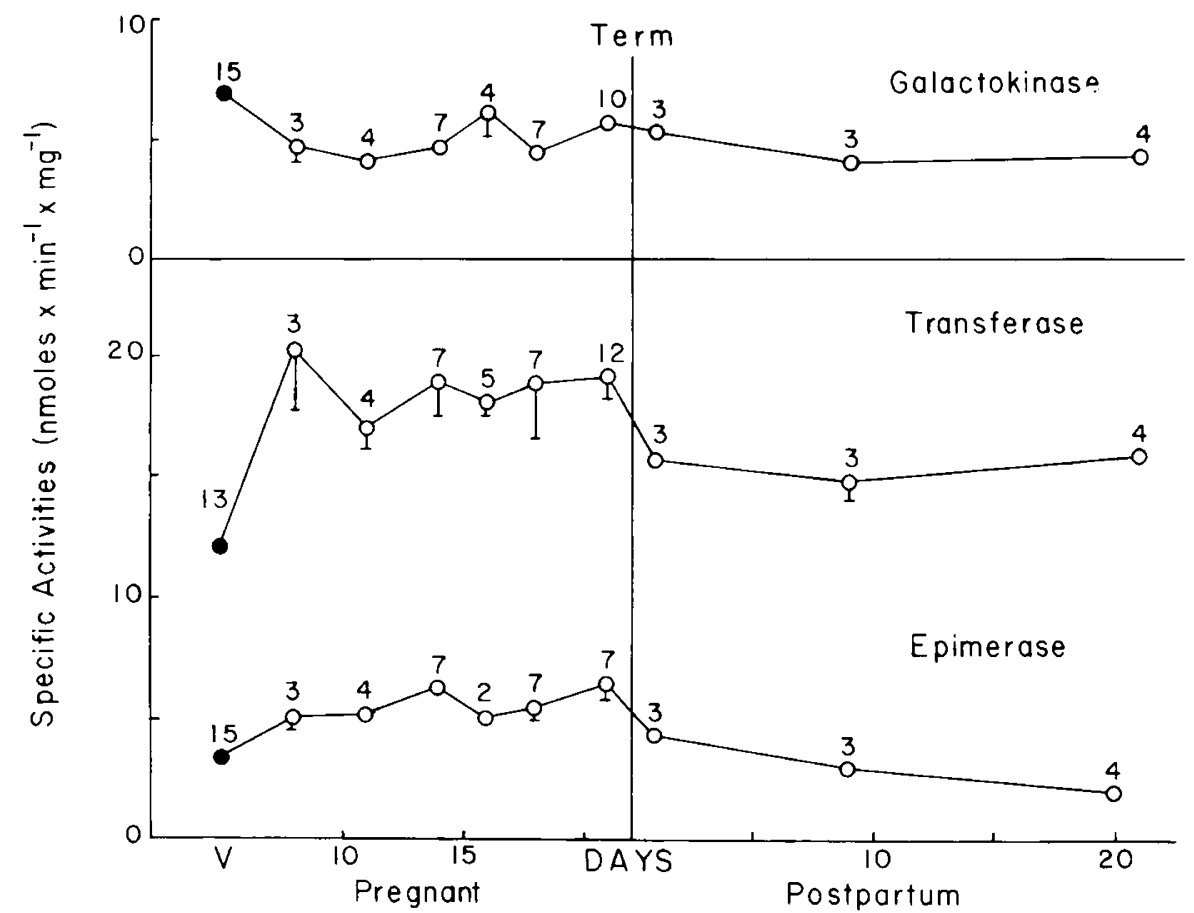

Fig. 1. Changes in the levels of the galactose-metabolizing enzymes in rat liver during pregnancy and lactation. Upper panel, sp act of galactokinase in liver of virgin $(V)(\bullet)$, pregnant, and lactating females $(O)$. Lower panel, transferase and epimerase activities in the same animals. Data points represent the average \pm SEM for the number of animals shown above each data point. Some SEM are not visible because they are less than the size of the symbol. Enzyme activities are expressed as nmol of product formed $/ \mathrm{min} / \mathrm{mg}$ soluble protein. The data for transferase and epimerase during pregnancy are significantly different from that found in the virgin where $p \leq 0.05$ is acceptable. The data for galactokinase during pregnancy are significantly different from the virgin except for day 14 and term. Other details are given in the text. 


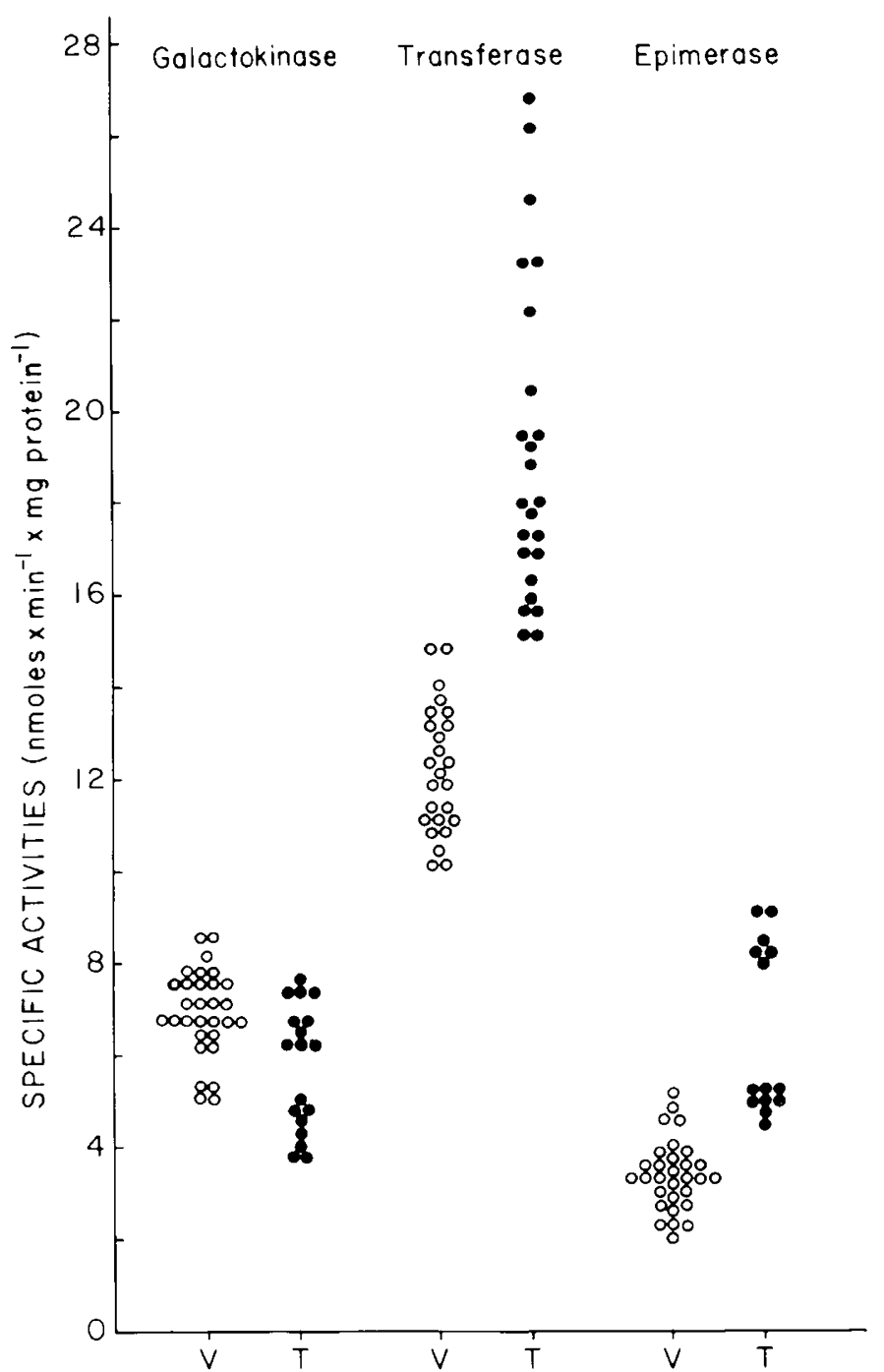

Fig. 2. Comparison of the ranges of enzyme specific activities for virgin and term maternal livers. The data shown represent duplicate enzyme assays of liver from each animal. Enzyme sp act of virgin $(V)$ and term $(T)$ rat liver are given as depicted from left to right, galactokinase, transferase, and epimerase.

Table 1. Total activity ( $\mu \mathrm{mol} / \mathrm{min}$ ) of galactose-metabolizing enzymes/liver of pregnant rats*

\begin{tabular}{ccccc}
\hline $\begin{array}{c}\text { Days of } \\
\text { pregnancy }\end{array}$ & $\begin{array}{c}\text { Body wt } \\
(\mathrm{g})\end{array}$ & Galactokinase & Transferase & Epimerase \\
\hline 0 & 200 & 2.81 & 5.43 & 1.34 \\
7 & 208 & 2.12 & 9.02 & 2.26 \\
14 & 227 & 2.31 & 9.27 & 3.07 \\
21 & 284 & 3.50 & 11.73 & 3.95 \\
\hline
\end{tabular}

* The average relative wt of the liver $/ 100 \mathrm{~g}$ body wt throughout pregnancy is $2.8 \mathrm{~g}$, and the average concentration of soluble protein is $77 \mathrm{mg} / \mathrm{g}$ liver.

These values were calculated using the sp act of each enzyme, the concentration of soluble protein/g of liver, and the increase in liver wt that occurs during gestation. The pattern of change differed for each enzyme. Galactokinase activity decreased slightly from the virgin level during the gravid state but showed a modest increase of about $25 \%$ by term. Transferase activity was double the virgin level by the 7 th day and remained essentially constant until term. Total epimerase activity linearly in- creased during pregnancy, reaching a level at term three times that found in virgin liver.

Concentration dependence of transferase activity in pregnant rat. The apparent Michaelis-Menten constants were determined for both substrates of the reaction catalyzed by transferase in liver of pregnant and nonpregnant rats. Figure 3 shows Lineweaver-Burk reciprocal plots of the composite data obtained when UDPglucose was the varied substrate in several replicate studies. Substrate inhibition was observed at 1 and 2 mM UDPglucose for both groups, and these data were not used in determining the linear plots. At all concentrations of UDPglucose, the activity of transferase in the pregnant liver was 1.5 -fold greater than that in the virgin tissue. The values for the apparent Michaelis-Menten constants for each individual study were used to calculate the mean and SEM for each group. The mean for the pregnant group was significantly greater $(p<0.001)$ for each group than in the nonpregnant, being $31.89 \pm 1.81(n=7)$ and

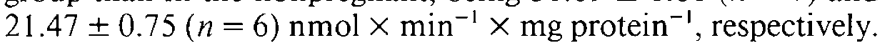
The $\mathrm{Km}$ for this substrate in the pregnant group was $0.14 \pm 0.02$ $\mathrm{mM}$, a value not statistically different from that of the nonpregnant rats $0.12 \pm 0.02$. As with UDPglucose, substrate inhibition is seen at high galactose-1-P concentrations (Fig. 4) which has been described previously (9). The pregnant animal exhibits a significantly $(p<0.01)$ elevated $\mathrm{V}_{\max }$ over that of the virgin, being $25.50 \pm 0.77(n=3)$ and $20.17 \pm 0.70(n=3) \mathrm{nmol} \times$ $\mathrm{min}^{-1} \times \mathrm{mg}$ protein ${ }^{-1}$, respectively. Km values with respect to galactose-1-P were similar $0.12 \pm 0.01 \mathrm{mM}$ for the pregnant group and $0.09 \pm 0.01$ for the nonpregnant.

IEF of pregnant and nonpregnant rat liver. Multiple isozymic forms of transferase have been reported by starch gel electrophoresis (15) agarose gel electrophoresis (14) and polyacrylamide $\operatorname{IEF}(13,16)$ where four (17) to six bands between $\mathrm{pH} 5.30$ and 5.80 have been described for human liver (18). The microheterogeneity of liver transferase was examined by IEF of the nonpregnant and pregnant rat. The resulting patterns are shown in Figure 5. The liver of the virgin animal displayed eight bands. No difference in the pattern was apparent in the enzyme of pregnant rat liver. Differences in intensity are not apparent because the same amount of enzyme activity from pregnant and virgin rat liver homogenate are loaded onto the gel.

Enzyme activity after parturition. Changes in the specific activities of the liver enzymes also occur after parturition, as revealed in Figure 1. After delivery of the pups, the levels of all three enzymes decreased. Galactokinase levels during the nursing period were slightly lower than at term. By 21 days postpartum,

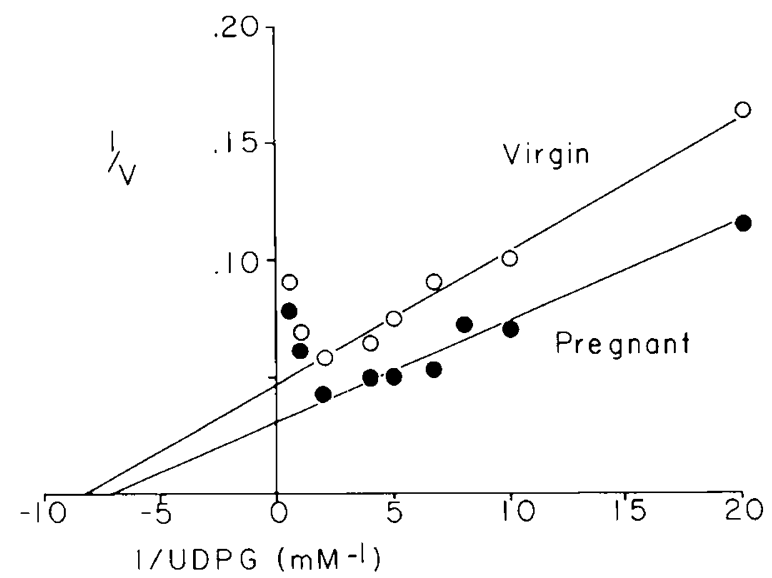

Fig. 3. Concentration dependence of transferase activity in near-term pregnant and virgin female rat liver with respect to UDPglucose (UDPG) at $0.35 \mathrm{mM}$ galactose-1-P. Sp act $(V)$ are expressed as nmol of product formed $/ \mathrm{min} / \mathrm{mg}$ soluble protein. The data points represent the average of seven pregnant and six virgin livers, each assayed in duplicate. The lines were computed by linear regression analysis of all the values, excluding those demonstrating substrate inhibition. 
the level was $4.33 \pm 0.25(n=4), \mathrm{nmol} \times \mathrm{min}^{-1} \times \mathrm{mg}_{\text {protein }}{ }^{-1}$ a value comparable to that found at mid-pregnancy but lower than that found in virgin rat liver. Transferase sp act fell sharply 1 day after delivery from $19.17 \pm 1.04(n=12)$ at term to 15.70

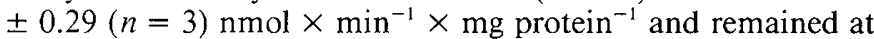
this level throughout the nursing period. All of the postpartum values were significantly lower than that found during pregnancy $(p=0.01)$. The pattern of change observed for epimerase sp act paralleled the drop seen in transferase after delivery; however, epimerase activity gradually decreased further to values at or below that of virgin rat liver.

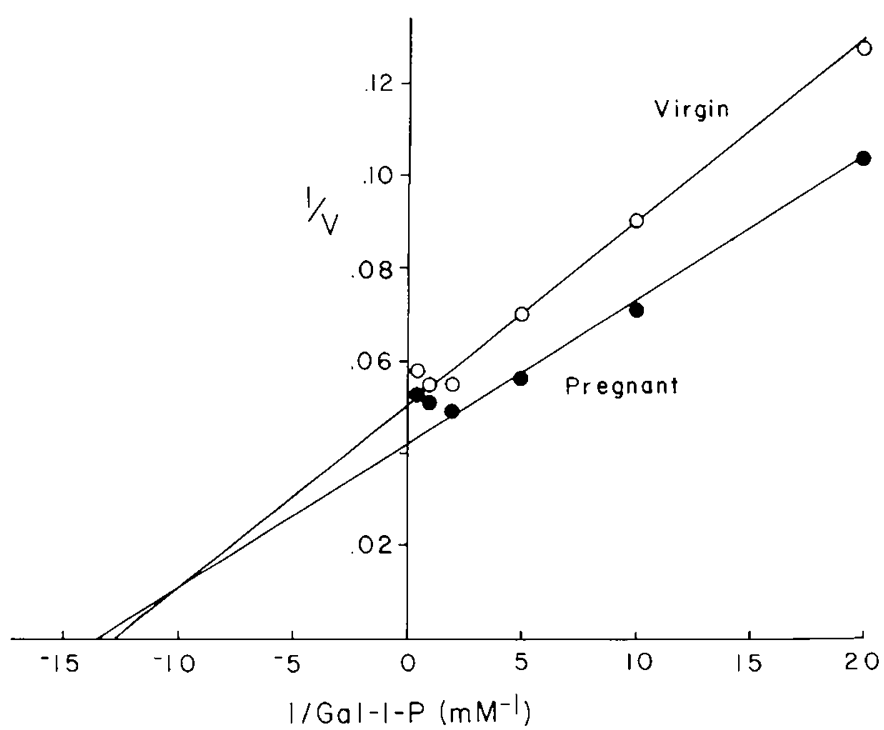

Fig. 4. Concentration dependence of transferase activity in near-term pregnant and virgin female rat livers with respect to galactose-1-P (Gal1-P) at $0.25 \mathrm{mM}$ UDPglucose. The data points are the average of duplicate assays performed on tissue from three pregnant and three virgin animals with the line computed by linear regression analysis, excluding values exhibiting substrate inhibition.
Enzyme activity in fetus and suckling. Changes in the sp act of the galactose metabolizing enzymes during fetal development and in suckling rats postpartum are shown in Figure 6. The pattern of change of the sp act of each enzyme is different from fetal life until weaning. During fetal development, galactokinase remained relatively constant until after day 16 of pregnancy when it doubled at term, subsequently peaked at 7 days of age, and decreased to adult levels by 21 days. The transferase pattern is one of doubling between 12 and 14 days of fetal life, with a plateau until birth followed by a rise to a peak at 8 days of age which is almost three times the fetal liver value. Epimerase, by contrast, stays constant and higher than adult values through fetal life and in the early days postpartum, decreasing to adult

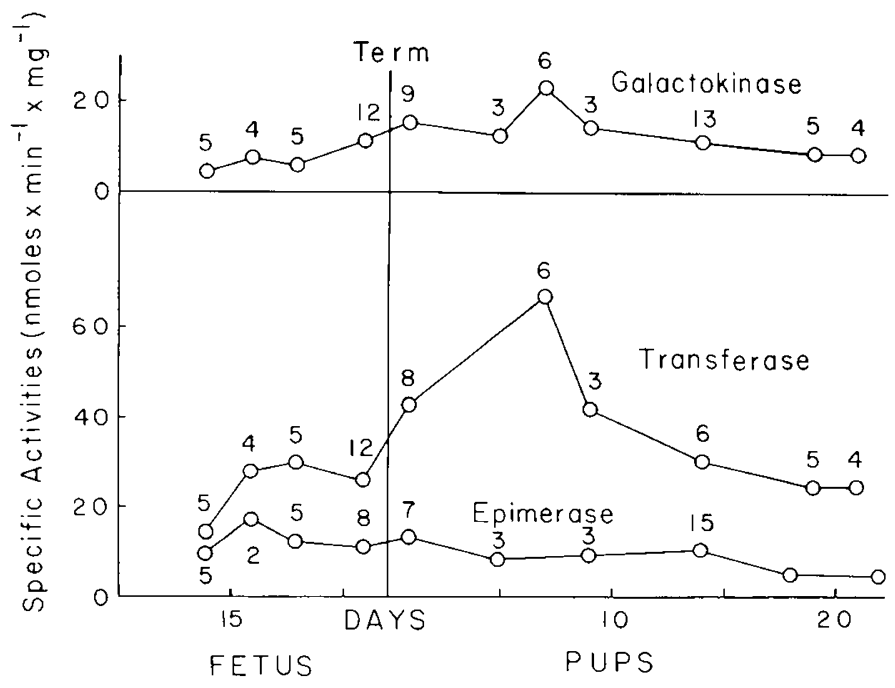

Fig. 6. Changes in the levels of the galactose-metabolizing enzymes of rat fetal and pup liver. Upper panel presents changes in the sp act of galactokinase in the fetal rat and pup liver. Lower panel presents transferase and epimerase activities in the same animals. Details are given in Figure 1.

\section{ANODE}
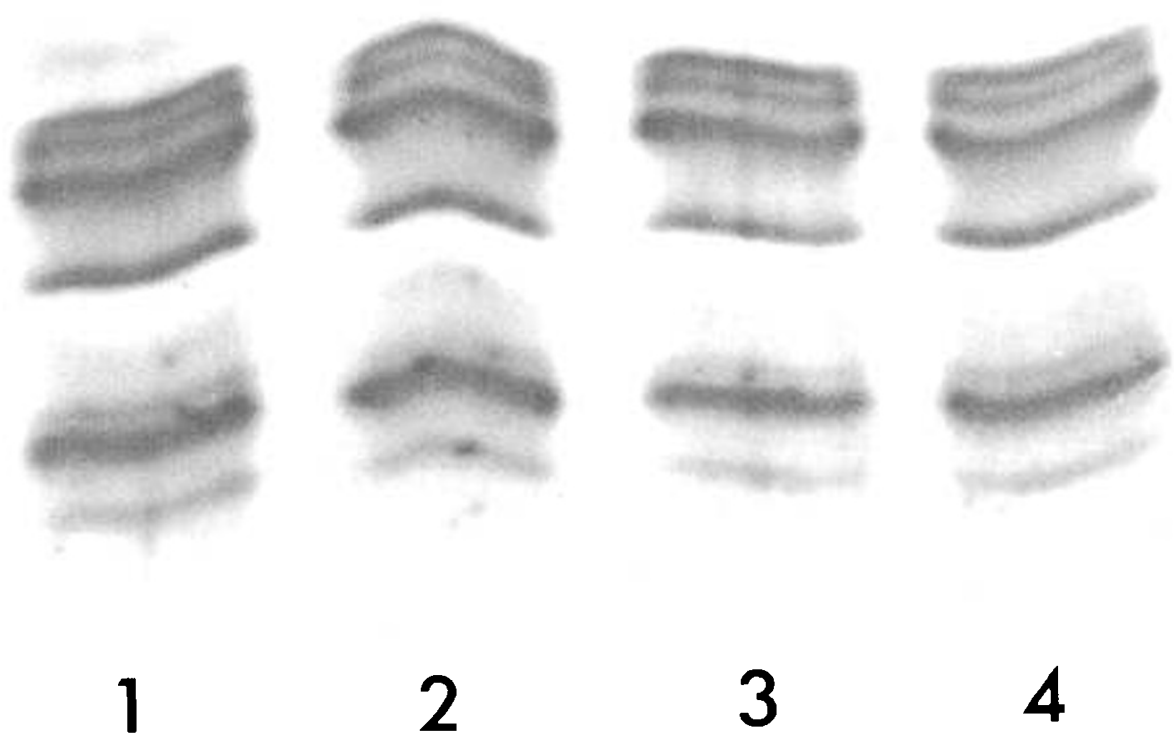

Fig. 5. Isozyme patterns of transferase in nonpregnant (lanes 1 and 2) and pregnant (lanes 3 and 4) liver after IEF on a narrow range (pH 5-7), high resolution IEF polyacrylamide gel. The photograph was taken after the gel was enzymatically stained for transferase. 
level after 15 days of age. The changes after birth correspond to those reported previously for galactokinase by Cuatrecasas and Segal (8) transferase by Bertoli and Segal (9) and epimerase by Cohn and Segal (19). The present data were obtained for comparative purposes.

A comparison of $\mathrm{sp}$ act of the fetal liver enzymes with the pregnant female can be made by examining the data of Figures 1 and 5. The fetal and maternal galactokinase sp act for each group were $7.78 \pm 0.3(n=20)$ and $4.67 \pm 0.3(n=30) \mathrm{nmol} \times$ min $^{-1} \mathrm{mg}$ protein ${ }^{-1}$, respectively, and results from ANOVA support those obtained by Student's $t$ test with a $p$ value of 0.001 . The average fetal transferase was $24.1 \mathrm{nmol} \times \mathrm{min}^{-1} \mathrm{mg}$ protein $^{-1}$, compared to that of the group of maternal livers at 18.88 $\pm 0.6, p<0.001$. Epimerase sp act of the fetal liver was twice that of the dam $11.64 \pm 0.3$ as $5.78 \pm 0.2, p<0.001$. The total fetal enzyme activity of all three enzymes of the fetal tissue is, however, low compared to the mother's liver, considering that the concentration of protein/g liver is $50 \%$ of that of the mother, and the fetal liver has a relative size $6 \%$ of the liver of the pregnant animal $(11,12)$.

\section{DISCUSSION}

Our results indicate that there are significant changes in the sp act and total liver activity of the galactose-metabolizing enzymes during pregnancy in the rat. That the changes are specific for different enzymes is demonstrated by the different pattern of enzyme changes for galactokinase, transferase, and epimerase. The effect of pregnancy on the sp act of a number of enzymes has been reported $(11,12,20)$. Some enzymes such as pyruvate kinase and phosphoenolpyruvate carboxylase are unchanged in pregnant liver; others, such as ATP citrate lyase and alanine amino transferase, are decreased and glucose 6-phosphate dehydrogenase is increased.

$\mathrm{Sp}$ act expressed in various terms such as per $\mathrm{mg}$ protein, $\mathrm{mg}$ tissue, or whole organ, indicate how these factors affect the enzymic patterns and the total metabolic capacity of the tissue. Previous reports have shown that although the size of the liver increases during pregnancy above that of nonpregnant rats (11, 12), this increase is not accompanied by a parallel increase in hepatic protein concentration which remains similar to that of the nonpregnant rat liver. Therefore, the same patterns of enzyme activity are obtained whether expressed as $\mathrm{U} / \mathrm{mg}$ protein or as $\mathrm{U} / \mathrm{g}$ of liver. The increase in liver wt in pregnancy, therefore, together with the changes in enzyme activity, lead to augmented enzyme capacity for handling the conversion of galactose to glucose (Table 1).

Precisely how the changes in the total activity of the galactosemetabolizing enzymes relate to overall metabolic disposition of galactose by pregnant rats remains to be determined. Whether the marked increase in total transferase and epimerase activity (Table 1) can account for increased galactose metabolism is a point for speculation. The rate-regulating reaction in this multienzyme pathway, if there is one, has not been clearly kinetically identified (21). Because galactose metabolism articulates with that of glucose the complex changes in carbohydrate metabolism in pregnancy $(5,6)$ may also be an important factor.

Although there are a multiplicity of events associated with pregnancy, the altered hormonal state of the pregnant rat may be responsible for the changes observed in transferase and epimerase activity. That progesterone may be an important factor is the previous observation that progesterone administration to galactosemic individuals enhances their ability to oxidize galactose to $\mathrm{CO}_{2}$ and that progesterone given to rats affords protection from cataract development (3). These findings may have a bearing on the observation that pregnant dams do not get cataracts during pregnancy. But only $48 \mathrm{~h}$ after parturition, when plasma progesterone decreases and when we observe a decrease in transferase activity, fully developed cataracts were observed.

The fetus, by contrast, develops cataracts when a high galactose diet is fed to the pregnant rat (2). Whatever the factors which augment the total activity and sp act of the hepatic galactosemetabolizing enzymes in the mother and affords protection from galactose toxicity, they obviously do not prevent damage to the fetus from galactose, which equilibrates across the placenta with the high levels in the maternal circulation. Although the fetal hepatic enzyme sp act are higher than sp act in maternal tissue, the fetal organ is so small that the capacity for metabolic disposition of galactose cannot cope with the burden. We have not measured enzyme activity in tissues other than liver. It may well be that similar changes occur elsewhere and that the sparing of the maternal lens from galactose toxicity may be due to local metabolic effects in the lens itself.

The enzyme changes that occur in the maternal and neonatal liver after parturition deserve some comment. With the loss of the pregnant state, the sp act of the maternal enzymes decrease (Fig. 1). Transferase remains higher than that of the nonpregnant tissue, but epimerase and galactokinase eventually revert to levels even somewhat lower than that seen in the virgin female. In newborn rats the high hepatic sp act of epimerase remains elevated until 15 days of age. In contrast, galactokinase and transferase sp act are programmed to increase to a maximum at about 8 days of age and then diminish to adult levels. Galactose metabolic studies of minced liver (22) with suckling rat hepatocytes (23) and perfused liver (24) show that young liver has a greater ability to metabolize galactose than adult tissue, thus giving functional significance to the high enzyme activities observed during the suckling period when galactose is ingested.

The increase in transferase sp act in the pregnant liver and the programmed increase in the neonatal liver during the suckling period indicate that the enzyme is capable of modulation in normal animals. The kinetic data demonstrating an increase in $V_{\max }$ of the enzyme reported here for tissue from pregnant animals and in neonatal liver reported previously (9) suggest that there may be increased amounts of active enzyme. Whether the locus is at the level of transcription or translation of the enzyme is not known. We did not find evidence for a difference in postranslational modification of the virgin and pregnant rat liver enzyme because similar isozyme patterns were obtained by IEF. From a speculative point of view, our findings may have important implications regarding possible new approaches to treatment of transferase deficiency galactosemia. At present, dietary therapy with galactose reduction is far from optimal (25). Even when the diagnosis is made at birth, the elimination of dietary galactose frequently fails to prevent mental retardation, ovarian failure, and late neurologic abnormalities (25-27). If these complications result from continued self-intoxication by galactose-1-phosphate formation from uridine diphosphate galactose as proposed by Gitzelmann (28), a pertinent new strategy would be the augmentation of the small amount of residual transferase activity present in affected individuals. If the regulatory factors acting to enhance transferase specific activity in pregnant and suckling rat liver can be determined, they may be able to play a role in such a new therapeutic approach.

Acknowledgments. We thank S. R. Pradhan and S. Fisher for their excellent technical assistance.

\section{REFERENCES}

1. Spatz M, Segal S 1965 Transplacental galactose toxicity in rats. J Pediatr $67: 438-446$

2. Segal S, Bernstein H 1963 Observations on cataract formation in the newborn offspring of rats fed a high-galactose diet. J pediatr 62:363-370

3. Pesch L, Segal S, Topper YJ 1960 Progesterone effects on galactose metabolism in prepubertal patients with congenital galactosemia and in rats maintained on high galactose diets. J Clin Invest 39:178-184

4. Unakar NJ, Smart T, Reddan JR, Devlin I 1979 Regression of cataracts in the offspring of galactose fed rats. Ophthalmic Res 11:52-64

5. Herrera E, Knopp RH, Freinkel N 1969 Carbohydrate metabolism in pregnancy: VI: plasma fuels, insulin, liver composition, gluconeogensis and nitrogen metabolism during late gestation in the fed and fasted rat. J Clin 
Invest 48:2260-2272

6. Metzger BE, Hare JW, Freinkel N 1971 Carbohydrate metabolism in pregnancy: IX: plasma levels of gluconeogenic fuels during fasting in the rat. $\mathrm{J}$ Clin Endocrinol Metab 33:869-872

7. Diamant YZ, Shafrir E 1972 Enzymes of carbohydrate and lipid metabolism in the placenta and liver of pregnant rats. Biochim Biophys Acta 279:424430

8. Cuatrecases P, Segal S 1965 Mammalian galactokinase. J Biol Chem 240:23822388

9. Bertoli D, Segal S 1966 Developmental aspects and some characteristics of mammalian galactose 1-phosphate uridyltransferase. J Biol Chem 241:40234029

10. Rogers S, Segal S 1981 Changing activities of galactose-metabolizing enzymes during perfusion of suckling-rat liver. Am J Physiol 240:E333-E339

11. Kuo S, Stipanuk HM 1984 Changes in cysteine dioxygenase and cysteinesulfinate decarboxylase activities and taurine levels in tissues of pregnant or lactating rat dams and their fetuses or pups. Biol Neonate 46:237-248

12. Muraca M, Leyten R, Fevery J 1984 Conjugation and maximal biliary excretion of bilirubin in the rat during pregnancy and lactation and during estroprogestogen treatment. Hepatology 4:633-638

13. Kelley RI, Harris H, Mellman WJ 1983 Characterization of normal and abnormal variants of galactose-1-phosphate uridyl transferase (EC 2.7.7.12) by isoelectric focusing. Hum Genet 63:274-279

14. Sparkes MC, Crist M, Sparkes RS 1977 Improved technique for electrophoresis of human galactose-1-phosphate uridyl transferase (EC 2.7.7.12). Hum Genet 40:93-97

15. Ng WG, Bergen WR, Fields M, Donnell GN 1969 An improved electrophoretic procedure for galactose-1-phosphate uridyl transferase: demonstration of multiple activity bands with the Duarte variant. Biochem Biophys Res Commun 37:354-362

16. Vaccaro AM, Muscillo M, Mandara I, Salvioli R 1982 Improved isoelectric focusing of normal and variant forms of erythrocyte galactose-1-phosphate uridyl transferase. Electrophoresis 3:58-61

17. Banroques J, Gregori C, Dreyfus JC 1983 Purification of human liver uridylyl transferase and comparison with the erythrocyte enzyme. Biochimie 65:713

18. Schapira F, Gregori C, Banroques J 1978 Microheterogeneity of human galactose-1-phosphate uridyl transferase. Isoelectric focusing results. Biochem Biophys Res Commun 80:291-297

19. Cohn R, Segal S 1969 Some characteristics and developmental aspects of rat uridine diphosphogalactose 4-epimerase. Biochim Biophys Acta 171:333341

20. Herding HR, Rosen F, Nicol CA 1966 Effects of pregnancy on several cortisolresponsive enzymes in rat liver. Am J Physiol 211:1361-1365

21. Cohn R, Segal S 1973 Galactose metabolism and its regulation. Metabolism 22:627-642

22. Segal S, Roth H, Bertoli D 1963 Galactose metabolism by rat liver tissue: influence of age. Science 142:1311-1313

23. Rogers S, Guerra M, Segal S 1983 Galactose metabolism in suckling and adult isolated rat hepatocytes. Pediatr Res 17:609-616

24. Berman WF, Rogers SR, Bautista JO, Segal S 1978 Galactose and glucose metabolism in the isolated perfused suckling and adult rat liver. Metabolism 27:1721-1731

25. Fishler K, Koch R, Donnell GN, Wenz E 1980 Developmental aspects of galactosemia from infancy to childhood. Clin Pediatr 19:38-44

26. Gitzelmann R, Steinmann B 1984 Galactosemia: How does long-term treatment change the outcome? Enzyme 32:37-46

27. Lo W, Packman S, Nash S, Schmidt K, Ireland S, Diamond I, Ng W, Donnell G 1984 Curious neurologic sequelae in galactosemia. Pediatrics 73:309-312

28. Gitzelmann R 1969 Formation of galactose-1-phosphate from uridine diphosphate galactose in erythrocytes from patients with galactosemia. Pediatr Res 3:279-286 